\title{
BMJ Open Association of tobacco use and other determinants with pregnancy outcomes: a multicentre hospital-based case- control study in Karachi, Pakistan
}

\author{
Shafquat Rozi, ${ }^{1}$ Zahid Ahmad Butt, ${ }^{2}$ Nida Zahid, ${ }^{1}$ Saba Wasim, ${ }^{3}$ Kashif Shafique ${ }^{4,5}$
}

To cite: Rozi S, Butt ZA, Zahid N, et al. Association of tobacco use and other determinants with pregnancy outcomes: a multicentre hospital-based case-control study in Karachi, Pakistan. BMJ Open 2016:6:e012045. doi:10.1136/bmjopen-2016012045

- Prepublication history for this paper is available online. To view these files please visit the journal online (http://dx.doi.org/10.1136/ bmjopen-2016-012045).

Received 28 March 2016 Revised 9 August 2016 Accepted 23 August 2016

CrossMark

For numbered affiliations see end of article.

Correspondence to Dr Shafquat Rozi; shafquat. rozi@aku.edu

\section{ABSTRACT}

Objectives: The study aimed to identify the effects of maternal tobacco consumption during pregnancy and other factors on birth outcomes and obstetric complications in Karachi, Pakistan.

Design: A multicentre hospital-based case-control study.

Setting: Four leading maternity hospitals of Karachi. Participants: A random sample of 1275 women coming to the gynaecology and obstetric department of selected hospitals for delivery was interviewed within 48 hours of delivery from wards. Cases were women with adverse birth outcomes and obstetric complications, while controls were women who had normal uncomplicated delivery.

Primary and secondary outcome measures: Adverse birth outcomes (preterm delivery, low birth weight, stillbirth, low Apgar score) and obstetric complications (antepartum haemorrhage, caesarean section, etc).

Results: Final multiple logistic regression analysis revealed that with every 1 year increase in age the odds of being a case was 1.03 times as compared with being a control. Tobacco use (adjusted OR (aOR): $2.24 ; 95 \% \mathrm{Cl}$ 1.56 to 3.23 ), having no slits in the kitchen (proxy indicator for indoor air pollution) $(\mathrm{aOR}=1.90 ; 95 \% \mathrm{Cl}$ 1.05 to 3.43 ), gravidity ( $\mathrm{aOR}=0.83 ; 95 \% \mathrm{Cl} 0.73$ to 0.93 ), non-booked hospital cases (aOR=1.87; $95 \% \mathrm{Cl} 1.38$ to 2.74), history of stillbirth ( $\mathrm{aOR}=4.06 ; 95 \% \mathrm{Cl} 2.36$ to 6.97), miscarriages ( $\mathrm{aOR}=1.91 ; 95 \% \mathrm{Cl} 1.27$ to 2.85 ) and preterm delivery (aOR=6.04; $95 \% \mathrm{Cl} 2.52$ to 14.48$)$ were significantly associated with being a case as compared with control.

Conclusions: This study suggests that women who had adverse pregnancy outcomes were more likely to have exposure to tobacco, previous history of adverse birth outcomes and were non-booked cases. Engagement of stakeholders in tobacco control for providing health education, incorporating tobacco use in women in the tobacco control policy and designing interventions for tobacco use cessation is warranted. Prenatal care and health education might help in preventing such adverse events.

\section{INTRODUCTION}

Low birth weight (LBW) of the infant is a challenging multifaceted public health
Strengths and limitations of this study

- Our study included a robust method of recruitment to reduce classification of the outcome.

- Being a multicentre hospital-based study catering to patients from different ethnic and socioeconomic backgrounds indicates that our results can be generalised.

- One of the limitations of this study was that most of the information was self-reported; therefore, it was prone to reporting bias. However, we had given extensive training to our data collectors to retrieve participant's information as accurately as possible. Numerous studies have shown that self-reported smoking is reliable method of gathering information.

- Ideally, serum cotinine levels would have been a better measure; however, it was not possible to obtain blood samples in our study.

problem, as it varies from $4.5 \%$ in most developed countries to almost $50 \%$ in some of the least developed countries. ${ }^{1}$ The prevalence of LBW is high in developing countries $(18.5 \%)$, with the highest prevalence in South Asia (27\%) including Pakistan ${ }^{2}$ and India. ${ }^{1}$ Stillbirth is another important adverse birth outcome. Globally, 3.9 million stillbirths are reported and unfortunately $97 \%$ of them are occurring in the developing world. ${ }^{3}$

There are a number of risk factors that may be associated with adverse birth outcomes and obstetric complications. Among them, tobacco use is a major public health problem globally. According to the WHO, there are about one billion smokers worldwide. ${ }^{4}$ Smoking prevalence among women varies markedly across countries; it is $7 \%$ in developing countries and $24 \%$ in developed countries. ${ }^{5}$ Tobacco use is common in Pakistan; about $34 \%$ of men and $12.5 \%$ of women use different forms of tobacco regularly. ${ }^{5}$ Notably, $3.2 \%$ of pregnant women had ever been a regular cigarette smoker in Pakistan. ${ }^{6}$ Women 
who smoke cigarettes have higher rate of gynaecological complications $^{7}$ and decreased fertility potential. ${ }^{8-10}$ Smoking increases the level of nicotine and carbon monoxide in the blood, which causes serious complications including increased rate of spontaneous abortion, ${ }^{11}$ premature delivery, ${ }^{11}{ }^{12} \mathrm{LBW},{ }^{11}{ }^{13}{ }^{14}$ placenta praevia, bleeding during pregnancy, premature rupture of membranes and stillbirths. ${ }^{15-17}$ Other adverse outcomes include small for gestational age (SGA) babies, ${ }^{13} 18$ miscarriages, ${ }^{19}$ lipid abnormalities, ${ }^{20}$ increased risk for hypertension and gestational diabetes. ${ }^{21}$

Another important aspect is the increasing use of alternative forms of tobacco. According to the National Health Survey (NHS) of Pakistan, nearly $10 \%$ of females aged 25-64 years reported regular use of chewing tobacco or snuff, and over $7 \%$ of women smoked 'chillum' or 'huqqa' which is also a concern as smokeless tobacco use is increasingly associated with maternal cigarette smoking. ${ }^{22-27}$ Additionally, tobacco, either chewed, applied orally, or smoked actively or passively, increases stillbirths by nearly three folds, reduces birth weight by $100-400 \mathrm{~g}$, significantly increases placental weight and is also associated with high foetal mortality. ${ }^{24}$ The NHS of Pakistan reported that $31 \%$ of pregnant women who had ever tried cigarette smoking had transitioned to regular use and among these regular users, $76.9 \%$ admitted that they are currently smoking. ${ }^{5}$ Notably, the majority $(92 \%)$ of these women reported that smoking cigarettes or other tobacco products was permitted in their home. About half of the women reported that they and their young children were frequently or always exposed to indoor tobacco smoke. This has important implications as women and children are the most vulnerable in terms of experiencing the adverse effects of tobacco use. Second-hand smoke has been found to be associated with preterm birth ${ }^{28} 29$ and $\mathrm{LBW}^{30}$ among pregnant women.

There are other risk factors that may also be associated with such adverse pregnancy outcomes and could also be potential confounders of the association between tobacco use and birth outcomes. Malnourishment among females living in resource poor settings predisposes them to anaemia and infections due to inadequate food intake. ${ }^{31}{ }^{32}$ Studies from Zimbabwe and Bangladesh reported that maternal mid-arm circumference was strongly related with $\mathrm{LBW}^{33}$ and preterm birth. ${ }^{34}$ Moreover, females undergoing antenatal complications are at an increased risk of adverse pregnancy outcomes. ${ }^{34}$

Another important factor is indoor air pollution (IAP) from solid fuel use which has been linked to acute lower respiratory infections in children and adverse pregnancy outcomes. Systematic reviews with meta-analyses have reported the association between IAP and increased risk of LBW and stillbirth. ${ }^{35}$ Additional maternal risk factors such as primiparity, poor socioeconomic status, multiple gestations, premature rupture of membranes, hypertension and undernutrition can also contribute to adverse pregnancy outcomes. ${ }^{36} 37$
The majority of studies conducted in Pakistan on tobacco use have either been cross-sectional surveys ${ }^{5}$ or have focused primarily on school children ${ }^{38}$ and adolescents. ${ }^{39}$ Very few studies have focused on pregnant women and tobacco consumption. ${ }^{5}$ Awareness about tobacco use and its effect on women's health especially during pregnancy is lacking in Pakistan. Smoking and smokeless tobacco use among women is given low priority in public health programmes in Pakistan and scant attention is given to this issue by media. Even the public health messaging on media is focused on male members of the society and discussion of second-hand smoke is limited. To our knowledge, this is the first case-control study from Pakistan to identify the effects of maternal tobacco consumption and other factors during pregnancy on birth outcomes and obstetric complications.

\section{MATERIAL AND METHODS}

The study was designed as a multicentre hospital-based case-control study in Karachi, Pakistan. Karachi is the largest metropolitan city of Pakistan with a population estimated to be about 20 million. ${ }^{41}$ Study participants were enrolled from four leading maternity hospitals of Karachi (Civil Hospital, Jinnah Postgraduate Medical College Hospital, Lyari General Hospital and Sobhraj Maternity Hospital), from March to December 2011. The study population comprised all pregnant women aged $16-45$ years, coming to the selected hospitals from different ethnic, social, cultural and economic groups.

\section{Inclusion criteria \\ Cases}

Cases were pregnant women with singleton pregnancy presenting with the following outcomes:

(1) LBW (<2.5 kg) babies, (2) stillbirths (any child delivered after the 28th week of pregnancy who did not breathe afterwards or show any signs of life), (3) intra uterine deaths (foetus dies in uterus before the labour starts), (4) caesarean section due to foetal distress (decreased heart rate $<100 \mathrm{bpm}$ and/or passing meconium during labour), (5) antepartum haemorrhage (bleeding from the vagina occurring at any time after 28th week of pregnancy and before the birth of the child), (6) abruptio placentae (haemorrhage due to the partial separation of a placenta normally situated on the upper segment of the uterus), (7) placenta praevia( haemorrhage due to partial separation of a placenta abnormally situated on the lower segment of the uterus), (8) preterm labour (labour occurring before the 37th week of pregnancy) and (9) abnormal uterine action-prolonged labour (failed indication (delay in labour) due to primary uterine hypotonia in which contractions are weak, short and infrequent).

\section{Controls}

Controls were women with singleton term deliveries (37-40 weeks) having the following outcomes: 
(1) normal vaginal deliveries with or without episiotomy, (2) normal vaginal assisted (forceps or vacuum) deliveries and (3) caesarean sections due to cephalopelvic disproportion (obstructed labour), malpresentation of foetus and cord around the neck.

\section{Exclusion criteria}

Women with history of diabetes mellitus, gestational diabetes, hypertension before pregnancy, pre-eclampsia, eclampsia, severe anaemia (haemoglobin $<8 \mathrm{mg}$ ), cardiovascular diseases (valvular defects, congestive failures etc), chronic obstructive pulmonary disease, renal diseases, active infections (tuberculosis, hepatitis), epilepsy and severe complications in previous pregnancies and multiple births were excluded from the study.

\section{Sample size and sampling strategy}

Each hospital was treated as a stratum, cases and controls were selected randomly from hospitals. To determine sample size, a value of $\alpha=0.05$ and $\beta=0.2$ was specified and an OR of 1.6 was assumed. In Pakistan, $\sim 25 \%$ of newborns have LBW. ${ }^{42}$ Using these values, the required sample size was 1275 individuals with a design effect of $1.1^{42}$ and $10 \%$ non-response rate. A case to control ratio of 1:3 was used. A proportionate stratification technique was used to draw the samples from each hospital. In this technique, sample size of each stratum is proportionate to the population size of the stratum. The average number of delivered ladies was calculated in all five hospitals. Proportions (weight) of delivered ladies in each hospital were calculated by taking ratio between number of delivered ladies in each hospital and total number of delivered ladies in all five hospitals. The total number of deliveries was multiplied by calculated proportions (weight) of each hospital.

\section{Enrolment of cases and controls}

Trained data collectors interviewed mothers in obstetrics and gynaecology wards of the selected hospitals within 48 hours of delivery. Based on the case and control definition, the registers of the wards were searched for study participants who were selected randomly and then approached for interviews after receiving their consent.

\section{Definition of tobacco users}

All pregnant women who had regularly used tobacco products (smoke and smokeless) for the past 6 months, ${ }^{43}$ at least three times per week, were considered as tobacco users.

\section{Data collection procedure/tool}

One research coordinator and three female data collectors were hired for data collection who were trained by the principal investigator. Data collectors checked hospital records daily to obtain information about the expected number of women delivering babies on the day of visit to the hospitals. Field team visited the normal vaginal delivery room, recovery room and intensive care unit on a daily basis to gather the required information. After selection, an informed consent was taken from each woman. Study participants were explained the purpose of the study and any queries were addressed. Although this was not an intervention study, after the interview, data collectors provided information to participants about ill effects of tobacco use during pregnancy to make them aware of the health issues related with tobacco use.

\section{Questionnaire}

The questionnaire was developed in English and then translated into Urdu. The questionnaire contained questions regarding maternal sociodemographic information, previous and current obstetric characteristics, physical condition and tobacco consumption in any form during pregnancy. The last part of questionnaire focused on the main outcome of the study; Apgar score $(<7)$, weight of newborn, caesarean section, preterm birth and stillbirth.

\section{Ethical consideration}

Ethical approval for the study was obtained from the Aga Khan University's Ethical Review Committee. Written consent was obtained from all the hospitals' administration and individuals before an interview. Every precaution was taken to respect the privacy of participant.

\section{Data editing and entry}

The principal investigator and the data collectors edited filled questionnaires on a daily basis in the field and office. Data were double entered by two data entry operators in Epi Info V.6.04. ${ }^{44}$

\section{Statistical analysis}

Analyses were performed using Stata V.12.0. Descriptive analysis was carried out by calculating mean and SD for continuous variables and proportions for categorical variables. Logistic regression analysis was performed to study the associations between tobacco use and other factors and adverse pregnancy outcomes. ${ }^{45}$ Crude OR and their 95\% CI were calculated. Those variables with $\mathrm{p}$ value $\leq 0.25$, or biological or social importance, were selected for multiple logistic regression analysis. ${ }^{45}$ Adjusted ORs (AOR) and their 95\% CIs were obtained from multiple logistic regression model. All potential confounders and biologically plausible interactions were evaluated.

\section{RESULTS}

A total of 1275 women (312 cases and 963 controls) with singleton births were recruited for this study. The median duration of marriage were 3 years $(\mathrm{IQR}=1.0$ 7.0 years) among cases, and 5 years ( $\mathrm{IQR}=3.0-9.0$ years) among controls with median gravidity of 2 children in both groups. Proportion of tobacco use was $42.3 \%$ among cases and $24.4 \%$ among controls. Tobacco use 
Table 1 Characteristics of cases and controls presenting at selected hospitals in Karachi, Pakistan

\begin{tabular}{|c|c|c|}
\hline Characteristics & $\begin{array}{l}\text { Cases } \\
\mathrm{n}(\%)\end{array}$ & $\begin{array}{l}\text { Controls } \\
\text { n (\%) }\end{array}$ \\
\hline \multicolumn{3}{|l|}{ Age of mother (years) } \\
\hline Mean (SD) & $25.3(4.8)$ & $26.0(4.6)$ \\
\hline \multicolumn{3}{|l|}{ Mother tongue of respondent } \\
\hline Urdu & $168(53.8)$ & $492(51.1)$ \\
\hline Sindhi & $31(9.9)$ & $88(9.1)$ \\
\hline Punjabi & $20(6.4)$ & 79 (8.2) \\
\hline Balochi & $28(9.0)$ & 99 (10.3) \\
\hline Pashto & $31(9.9)$ & $111(11.5)$ \\
\hline Others & $34(10.9)$ & $94(9.8)$ \\
\hline \multicolumn{3}{|l|}{ Educational level } \\
\hline No formal education & $114(36.5)$ & $353(36.7)$ \\
\hline $\begin{array}{l}\text { Primary and } \\
\text { secondary }\end{array}$ & $160(51.3)$ & $519(53.9)$ \\
\hline Intermediate & $26(8.3)$ & $66(6.9)$ \\
\hline $\begin{array}{l}\text { Graduate and post } \\
\text { graduate }\end{array}$ & $12(3.8)$ & $25(2.6)$ \\
\hline \multicolumn{3}{|l|}{ Religion } \\
\hline Muslim & $302(96.8)$ & $937(97.3)$ \\
\hline Christian & $1(0.3)$ & $8(0.8)$ \\
\hline Hindu & $9(2.9)$ & $18(1.9)$ \\
\hline \multicolumn{3}{|l|}{ Family system } \\
\hline Nuclear & $106(34.0)$ & $356(37.0)$ \\
\hline Joint & $206(66.0)$ & $607(63.0)$ \\
\hline \multicolumn{3}{|l|}{ Nature of house } \\
\hline $\begin{array}{l}\text { Kachchaa (made by } \\
\text { mud and wood) }\end{array}$ & $14(4.5)$ & $21(2.2)$ \\
\hline $\begin{array}{l}\text { Pakka (made by bricks } \\
\text { and cement) }\end{array}$ & $298(95.5)$ & $942(97.8)$ \\
\hline \multicolumn{3}{|l|}{ Work currently } \\
\hline No & 307 (98.4) & $952(98.9)$ \\
\hline Yes & $5(1.6)$ & $11(1.1)$ \\
\hline Gravidity median (IQR) & $2.0(1.0-3.0)$ & $2.0(3.0-4.0)$ \\
\hline $\begin{array}{l}\text { Years of marriage } \\
\text { median (IQR) }\end{array}$ & $3.0(1.0-7.0)$ & $5.0(3.0-9.0)$ \\
\hline \multicolumn{3}{|l|}{ No. of antenatal care visits } \\
\hline Mean (SD) & $6.6(3.6)$ & $6.5(3.2)$ \\
\hline \multicolumn{3}{|l|}{ Ever domestic violence } \\
\hline No & $306(98.1)$ & $947(98.3)$ \\
\hline Yes & $6(1.9)$ & $16(1.7)$ \\
\hline \multicolumn{3}{|c|}{ Gestational age when foetal movement started (weeks) } \\
\hline Mean (SD) & $20.7(2.3)$ & $20.7(2.2)$ \\
\hline \multicolumn{3}{|c|}{ Complication during current pregnancy } \\
\hline No & $192(61.5)$ & $765(79.4)$ \\
\hline Yes & $120(38.5)$ & $198(20.6)$ \\
\hline \multicolumn{3}{|c|}{ Immunisation done during this pregnancy } \\
\hline No & $65(20.8)$ & $216(22.4)$ \\
\hline Yes & 247 (79.2) & $747(77.6)$ \\
\hline \multicolumn{3}{|c|}{ Ultrasound done during this pregnancy } \\
\hline No & $8(2.6)$ & $19(2.0)$ \\
\hline Yes & $304(97.4)$ & $944(98.0)$ \\
\hline \multicolumn{3}{|c|}{ Duration between water break and delivery of baby (hours) } \\
\hline Median (IQR) & $13.0(6.0-36.0)$ & $6.0(2.0-14.0)$ \\
\hline \multicolumn{3}{|l|}{ Material/fuel use for cooking } \\
\hline Gas & $291(93.3)$ & $905(94.0)$ \\
\hline Wood and others & $21(6.7)$ & $58(6.0)$ \\
\hline
\end{tabular}

Continued
Table 1 Continued

\begin{tabular}{|c|c|c|}
\hline Characteristics & $\begin{array}{l}\text { Cases } \\
\text { n (\%) }\end{array}$ & $\begin{array}{l}\text { Controls } \\
\text { n (\%) }\end{array}$ \\
\hline \multicolumn{3}{|c|}{ Slits/window in the kitchen } \\
\hline No & $29(9.3)$ & $54(5.6)$ \\
\hline Yes & $283(90.7)$ & $909(94.4)$ \\
\hline \multicolumn{3}{|c|}{ Slits/window in the house } \\
\hline No & $12(3.8)$ & $26(2.7)$ \\
\hline Yes & $300(96.2)$ & $937(97.3)$ \\
\hline \multicolumn{3}{|c|}{ Exhaust fan in kitchen } \\
\hline No & $277(88.8)$ & $834(86.6)$ \\
\hline Yes & $35(11.2)$ & $129(13.4)$ \\
\hline \multicolumn{3}{|c|}{ Average time spent in kitchen while stove burning (hours } \\
\hline Mean (SD) & $1.9(0.9)$ & $1.9(0.9)$ \\
\hline \multicolumn{3}{|l|}{ Tobacco use } \\
\hline No & $180(57.7)$ & $728(75.6)$ \\
\hline Yes & $132(42.3)$ & $235(24.4)$ \\
\hline
\end{tabular}

between case (with adverse birth outcome) and controls was found to be significantly different (table 1).

Cases included 312 participants consisting of 62 preterm, 15 stillbirths, 9 intrauterine deaths and 137 with weight $<2.5 \mathrm{~kg}$. The average weight of baby among cases was $2.5 \mathrm{~kg}(\mathrm{SD}=0.6 \mathrm{~kg})$ and there were a total of 216 babies delivered by caesarean section. The control group comprised 963 women without any of these conditions (table 2).

Binary logistic regression analysis showed a significant association between tobacco use (smoke or smokeless) and adverse pregnancy outcome at the univariable level (OR: 2.27; 95\% CI 1.73 to 2.97). The estimated ORs of women who had history of any illness or previous adverse pregnancy or birth outcome were significantly higher among cases compared with controls (table 3).

Age of women was also associated with adverse pregnancy outcome. For educational level, family history of illness and gestational age, there were no significant difference found between cases and controls. Cases were more likely to cook in kitchens without a slit/window (a proxy indicator for indoor pollution) ( $\mathrm{OR}=1.7 ; 95 \%$ CI 1.1 to 2.8 ) as compared with controls.

The final multiple logistic regression analysis indicated that the odds of tobacco use among cases were 2.24 times compared with controls (OR: 2.24; 95\% CI 1.56 to 3.23) after adjusting for other variables in the model. Age (AOR=1.03; 95\% CI 1.0 to 1.1), no slits in the kitchen (AOR: $1.90 ; 95 \%$ CI 1.05 to 3.43 ), gravidity $(\mathrm{AOR}=0.83$; $95 \%$ CI 0.73 to 0.93 ), non-booked hospital cases (AOR=1.87; 95\% CI 1.38 to 2.74), history of stillbirth $(\mathrm{AOR}=4.06 ; 95 \%$ CI 2.36 to 6.97$)$, miscarriages $(\mathrm{AOR}=1.91$; 95\% CI 1.27 to 2.85 ) and history of preterm delivery (AOR $=6.04 ; 95 \%$ CI 2.52 to 14.48 ) were significantly associated with being a case as compared with control (table 4).

\section{DISCUSSION}

In our study, tobacco use was significantly associated with adverse pregnancy and obstetrics complications. 
Table 2 Distribution of adverse pregnancy outcomes and obstetric complications among cases and controls at selected hospitals in Karachi, Pakistan

\begin{tabular}{|c|c|c|}
\hline Outcome & $\begin{array}{l}\text { Cases } \\
\text { n (\%) }\end{array}$ & $\begin{array}{l}\text { Controls } \\
\text { n (\%) }\end{array}$ \\
\hline \multicolumn{3}{|c|}{ Preterm delivery } \\
\hline No & $250(80.1)$ & $963(100)$ \\
\hline Yes & 62 (19.8) & - \\
\hline \multicolumn{3}{|c|}{ Caesarean section } \\
\hline No & $96(30.8)$ & $596(61.9)$ \\
\hline Yes & $216(69.2)$ & $367(38.1)$ \\
\hline \multicolumn{3}{|c|}{ Status of baby at birth } \\
\hline Alive & $288(92.3)$ & $963(100.0)$ \\
\hline IUD & $9(2.9)$ & - \\
\hline Stillbirth & $15(4.8)$ & - \\
\hline \multicolumn{3}{|c|}{ Birth weight of baby $(\mathrm{kg})$} \\
\hline Mean (SD) & $2.5(0.6)$ & $3.0(0.4)$ \\
\hline
\end{tabular}

Previous epidemiological studies have also reported that tobacco use ${ }^{14364647}$ is associated with preterm delivery. Smoking during pregnancy releases carbon monoxide and/or nicotine which induce foetal hypoxia. Foetal haemoglobin has a higher affinity for carbon monoxide than adult haemoglobin and the impact on the foetus is more severe than on the mother. ${ }^{48}$ Therefore, counselling of pregnant females about the detrimental effects of tobacco use is warranted.

Our study also reported that having no slits or windows in the kitchen; a proxy indicator for IAP resulted in an increased risk of adverse birth outcomes. IAP is one of the major risk factors for pneumonia-related morbidity, LBW and death in children worldwide. ${ }^{49}$ In Pakistan, the use of wood for cooking as fuel is common (>53\%) and overall biomass use including wood, crop residues and animal dung is $>70 \%$. ${ }^{49}$ Inhalation of smoke or particulate matter during cooking could have an adverse effect on pregnant women. ${ }^{35}$ Research from developing countries have described an association between the use of biomass fuels in open fires for cooking and LBW ${ }^{50} 51$ preterm birth $^{52}$ and SGA. ${ }^{53}$ Reports from surveys in India have shown an association between the use of biomass cooking fuel ${ }^{54}$ and stillbirths and LBW, ${ }^{55}$ findings which are consistent with our study. Therefore, in our context, awareness about IAP should be created especially among women as they are more likely to cook using biomass fuels; whereas, a general awareness campaign about IAP can be implemented through media.

In our study, we found that increasing age of the female was significantly associated with adverse pregnancy outcomes, a finding supported by several studies. ${ }^{56-58}$ Our study also identified women having previous history of stillbirth, miscarriage and preterm deliveries to be associated with adverse birth outcomes which is consistent with previous research. ${ }^{59}$

We found that the cases were less likely to be booked at the hospital as compared with controls. These cases had a history of previous pregnancy complications predisposing them to higher risk of adverse pregnancy outcomes. Plausibly, non-booking of women in hospitals, especially with previous history of adverse birth outcomes, is an indicator of lack of awareness of future pregnancy complications and could be a function of scarce resources. Therefore, creating awareness among these vulnerable women and frequent antenatal visits are essential to prevent such complications.

Another important finding was that blood transfusion was significantly associated with adverse pregnancy outcomes. Anaemia, a proxy indicator for blood transfusion is usually detected at the first antenatal visit. If anaemia persists, the foetus may not receive enough oxygen, and the risk of preterm is increased. In our study, cases may be unaware of their haemoglobin status and may have been severely anaemic because of missed prenatal checkups, therefore, at the time of delivery may be in desperate need of blood transfusion which could have led to the adverse pregnancy outcomes. However, in our study, we were unable to retrieve information regarding the haemoglobin levels of the pregnant female. Gravidity showed an inverse association with adverse birth outcomes which needs to be explored further to determine if women who were previously pregnant are more likely to take better care of themselves during future pregnancies.

Strengths of our study included a robust method of recruitment to reduce misclassification of the outcome and being a multicentre study catering to patients from different ethnic and socioeconomic backgrounds, thereby indicating that our results can be generalised. Most of the information in our study was self-reported, therefore, it was prone to reporting bias. ${ }^{60}$ However, any such bias is likely to be a non-differential misclassification, and the potential effect might be underestimation of the association because such biases tend to distort the associations towards null. So the potential effect of tobacco and other risk factors may even be more pronounced on adverse pregnancy outcomes, given that we assume that such misclassification exist in our study. Furthermore, we were not able to obtain serum cotinine levels which would have been a better measure. Although the effects of smoking and smokeless tobacco use are different on birth outcomes, we were unable to construct separate models for each exposure due to small numbers of smokers in our sample.

This study identified tobacco use as a very important risk factor for adverse birth outcomes in Pakistan. Commonly, tobacco use is either associated with respiratory disorders or oral cancers in Pakistan and is not associated with adverse birth outcomes. Our study highlights this issue and advocates for awareness among pregnant women and general population about the ill effects of tobacco use during pregnancy. Stakeholders in tobacco control including government, NGO's and health professionals should be made aware of this issue and should be engaged in order to prevent adverse outcomes in 
Table 3 Univariate analysis of factors associated with adverse birth outcomes and obstetric complications among cases and controls at selected hospitals in Karachi, Pakistan

\begin{tabular}{|c|c|c|c|c|}
\hline Characteristics & $\begin{array}{l}\text { Controls } \\
n=963\end{array}$ & $\begin{array}{l}\text { Cases } \\
n=312\end{array}$ & Crude OR & $95 \% \mathrm{Cl}$ \\
\hline \multicolumn{5}{|l|}{ Age of mother (years) } \\
\hline Mean (SD) & $26.0(4.6)$ & $25.3(4.8)$ & 0.96 & (0.90 to 1.0$)$ \\
\hline \multicolumn{5}{|l|}{ Educational level } \\
\hline No formal education & $353(36.7)$ & $114(36.5)$ & 1 & - \\
\hline Primary and secondary & $519(53.9)$ & $160(51.3)$ & 0.95 & $(0.73$ to 1.25$)$ \\
\hline Intermediate & $66(6.9)$ & $26(8.3)$ & 1.22 & (0.74 to 2.01$)$ \\
\hline Graduate and post graduate & $25(2.6)$ & $12(3.8)$ & 1.49 & (0.72 to 3.05$)$ \\
\hline \multicolumn{5}{|l|}{ Nature of house } \\
\hline Kachchaa (made by mud and wood) & $21(2.2)$ & $14(4.5)$ & 1 & - \\
\hline Pakka (made by bricks and cement) & $942(97.8)$ & $298(95.5)$ & 2.11 & (1.10 to 4.21$)$ \\
\hline \multicolumn{5}{|l|}{ Mother's history of illness } \\
\hline No & $959(99.6)$ & $305(97.8)$ & 1 & - \\
\hline Yes & $4(0.4)$ & $7(2.2)$ & 5.50 & (1.60 to 18.92$)$ \\
\hline \multicolumn{5}{|l|}{ Family history of illness } \\
\hline No & $556(57.7)$ & $191(61.2)$ & 1 & - \\
\hline Yes & 407 (42.3) & $121(38.8)$ & 0.86 & (0.72 to 1.10$)$ \\
\hline \multicolumn{5}{|l|}{ Years of marriage } \\
\hline Mean (SD) & $6.1(5.5)$ & $4.6(4.6)$ & 0.90 & (0.91 to 1.00$)$ \\
\hline \multicolumn{5}{|l|}{ Gravidity } \\
\hline Mean (SD) & $3.1(0.1)$ & $2.4(0.1)$ & 0.82 & (0.80 to 0.91$)$ \\
\hline \multicolumn{5}{|l|}{ History of miscarriage } \\
\hline No & $565(74.0)$ & $110(64.0)$ & 1 & - \\
\hline Yes & $198(26.0)$ & $62(36.0)$ & 1.61 & (1.13 to 2.31$)$ \\
\hline \multicolumn{5}{|l|}{ History of preterm delivery } \\
\hline No & $752(98.6)$ & $158(91.9)$ & 1 & - \\
\hline Yes & $11(1.4)$ & $14(8.1)$ & 6.00 & (2.71 to 13.60$)$ \\
\hline \multicolumn{5}{|l|}{ History of stillbirth } \\
\hline No & $718(94.1)$ & $142(82.6)$ & 1 & - \\
\hline Yes & $45(5.9)$ & $30(17.4)$ & 3.34 & (2.13 to 5.52$)$ \\
\hline \multicolumn{5}{|l|}{ Complication during previous pregnancy } \\
\hline No & $855(88.8)$ & $261(83.7)$ & 1 & - \\
\hline Yes & $108(11.2)$ & $51(16.3)$ & 1.52 & $(1.10$ to 2.21$)$ \\
\hline \multicolumn{5}{|l|}{ Booked in the hospital } \\
\hline Yes & $732(76.0)$ & $204(65.4)$ & 1 & \\
\hline No & $231(24.0)$ & $108(34.6)$ & 1.70 & (1.32 to 2.20$)$ \\
\hline \multicolumn{5}{|c|}{ Gestational age when foetal movement started (weeks) } \\
\hline Mean (SE) & $20.7(0.1)$ & $20.7(0.1)$ & 0.99 & $(0.94$ to 1.11$)$ \\
\hline No. of antenatal care visits & $6.5(0.1)$ & $6.6(0.2)$ & 1.02 & (0.99 to 1.04$)$ \\
\hline \multicolumn{5}{|l|}{ Micturition problem during pregnancy } \\
\hline No & $793(82.3)$ & $229(73.4)$ & 1 & \\
\hline Yes & $170(17.7)$ & $83(26.6)$ & 1.71 & (1.33 to 2.30$)$ \\
\hline \multicolumn{5}{|l|}{ Taken folic acid tablets } \\
\hline No & $611(63.4)$ & $199(63.8)$ & 1 & \\
\hline Yes & $352(36.6)$ & $113(36.2)$ & 1.02 & (0.81 to 1.30$)$ \\
\hline \multicolumn{5}{|l|}{ Complication during current pregnancy } \\
\hline No & $765(79.4)$ & $192(61.5)$ & 1 & \\
\hline Yes & $198(20.6)$ & $120(38.5)$ & 2.40 & (1.80 to 3.22$)$ \\
\hline \multicolumn{5}{|l|}{ Blood transfusion done } \\
\hline No & $914(94.9)$ & $286(91.7)$ & 1 & \\
\hline Yes & $49(5.1)$ & $26(8.3)$ & 1.70 & (1.0 to 2.80$)$ \\
\hline Duration between water break and deliv & $y$ (hours) & & & \\
\hline Mean (SE) & $12.3(0.7)$ & $27.8(4.6)$ & 1.03 & (1.02 to 1.03$)$ \\
\hline Slits/window in the kitchen & & & & \\
\hline Yes & 909 (94.4) & $283(90.7)$ & 1 & \\
\hline No & $54(5.6)$ & $29(9.3)$ & 1.72 & (1.11 to 2.76 ) \\
\hline Tobacco use & & & & \\
\hline No & $728(75.6)$ & $180(57.7)$ & 1 & \\
\hline Yes & $235(24.4)$ & $132(42.3)$ & 2.27 & (1.73 to 2.97 ) \\
\hline
\end{tabular}


Table 4 Multivariate analysis of factors associated with adverse birth outcomes and obstetric complications among cases and controls at selected hospitals in Karachi,

Pakistan

\begin{tabular}{|c|c|c|}
\hline Characteristics & Adjusted OR & $95 \% \mathrm{Cl}$ \\
\hline \multicolumn{3}{|l|}{ Tobacco use } \\
\hline No & 1 & \\
\hline Yes & 2.24 & (1.56 to 3.23$)$ \\
\hline Gravidity & 0.83 & (0.73 to 0.93$)$ \\
\hline Age of mother & 1.03 & (1.0 to 1.10$)$ \\
\hline \multicolumn{3}{|c|}{ Booked in hospital } \\
\hline Yes & 1 & \\
\hline No & 1.87 & (1.38 to 2.74$)$ \\
\hline \multicolumn{3}{|c|}{ History of preterm births } \\
\hline No & 1 & \\
\hline Yes & 6.04 & (2.52 to 14.48$)$ \\
\hline \multicolumn{3}{|c|}{ History of miscarriage } \\
\hline No & 1 & \\
\hline Yes & 1.91 & (1.27 to 2.85$)$ \\
\hline \multicolumn{3}{|l|}{ History of stillbirth } \\
\hline No & 1 & \\
\hline Yes & 4.06 & (2.36 to 6.97$)$ \\
\hline \multicolumn{3}{|c|}{ Slit/window in kitchen } \\
\hline Yes & 1 & \\
\hline No & 1.90 & (1.05 to 3.43$)$ \\
\hline \multicolumn{3}{|c|}{ Blood transfusion done } \\
\hline No & 1 & \\
\hline Yes & 3.06 & (1.68 to 5.57$)$ \\
\hline
\end{tabular}

pregnant women. We also found previous history of birth complications and non-booking in hospital as additional important predictors which suggest gaps in awareness of mothers about tobacco use during pregnancy. Improper ventilation (no slits in the kitchen) that is used as a proxy indicator for IAP was another significant predictor for adverse birth outcomes. Preventative measures either in the form of reducing the use of biomass fuels or reducing the time spent in kitchen during pregnancy could be warranted. However, future research is required on this issue to evaluate the feasibility of these measures and also to come up with a contextually relevant intervention.

\section{CONCLUSION}

Our study underscores the importance of antenatal care and health education about the effects of tobacco use and other factors during pregnancy which may lead to adverse pregnancy outcomes. We recommend engagement of stakeholders in tobacco control for providing health education and awareness, incorporating tobacco use among women in the tobacco control policy and for designing interventions for tobacco use cessation among women. Interventions aimed at improving prenatal care and health education during the antenatal period could be immediate measures which might help in reducing the burden of tobacco use and also prevent such adverse pregnancy-related events.
Author affiliations

${ }^{1}$ Department of Community Health Sciences, Aga Khan University, Karachi, Sindh, Pakistan

${ }^{2}$ School of Population and Public Health, University of British Columbia,

Vancouver, British Columbia, Canada

${ }^{3}$ Faculty of Biostatistics, College of Science and Health Professions, King Saud Bin Abdulaziz University, Riyadh, Saudi Arabia

${ }^{4}$ School of Public Health, Dow University of Health Sciences, Karachi, Sindh, Pakistan

${ }^{5}$ Institute of Health and Wellbeing, Public Health, University of Glasgow, Glasgow, UK

Acknowledgements The authors acknowledge all selected hospitals for their participation and support and are indebted to all pregnant women and our data collection team for their contribution.

Contributors SR contributed to analysis, interpretation, manuscript drafting and reviewing. ZAB and NZ were responsible for manuscript writing and reviewing the paper. SW helped in data cleaning, management and analysis. KS contributed to manuscript drafting and reviewing the paper. All authors saw and approved the final version of manuscript.

Funding This work was supported by a Seed Grant from the Aga Khan University. The funding agency had no role in the study design, data collection, data analysis, manuscript writing or publication.

Competing interests None declared.

Patient consent Obtained.

Ethics approval Ethical Review Committee (ERC) of Aga Khan University.

Provenance and peer review Not commissioned; externally peer reviewed.

Data sharing statement No additional data are available.

Open Access This is an Open Access article distributed in accordance with the Creative Commons Attribution Non Commercial (CC BY-NC 4.0) license, which permits others to distribute, remix, adapt, build upon this work noncommercially, and license their derivative works on different terms, provided the original work is properly cited and the use is non-commercial. See: http:// creativecommons.org/licenses/by-nc/4.0/

\section{REFERENCES}

1. Manna N, Sarkar BB, Basu G, et al. Socio-biological determinants of low birth weight: a community based study from rural field practice area of Medical College, Kolkata, West Bengal (India). IOSR J Dent Med Sci 2013;201:4.

2. Wardlaw TM. Low birthweight: country, regional and global estimates. UNICEF, 2004.

3. Goldenberg RL, Thompson $\mathrm{C}$. The infectious origins of stillbirth. Am J Obstet Gynecol 2003;189:861-73.

4. Tobacco facts. Secondary Tobacco facts. http://www.who.int/ tobacco/mpower/tobacco_facts/en/index.html (accessed on 20 Jun 2008).

5. Pakistan Medical Research Council. National health survey of Pakistan 1990-96. Health profile of people of Pakistan, 1998.

6. Bloch M, Althabe $\mathrm{F}$, Onyamboko $\mathrm{M}$, et al. Tobacco use and secondhand smoke exposure during pregnancy: an investigative survey of women in 9 developing nations. Am J Public Health 2008;98:1833-40.

7. World Health Organization. The tobacco health toll. Cairo: Regiona Office for the Eastern Mediterranean, 2005.

8. Stillman RJ, Rosenberg MJ, Sachs BP. Smoking and reproduction. Fertil Steril 1986;46:545.

9. Fielding JE. Smoking and women. N Engl J Med 1987;317:1343-5.

10. Ye X, Skjaerven $\mathrm{R}$, Basso $\mathrm{O}$, et al. In utero exposure to tobacco smoke and subsequent reduced fertility in females. Hum Reprod 2010;25:2901-6.

11. Lambers DS, Clark KE. The maternal and fetal physiologic effects of nicotine. Semin Perinatol 1996;2:115-26.

12. Andres RL, Day MC. Perinatal complications associated with maternal tobacco use. Semin Perinatol 2000;3:231-41.

13. Suzuki K, Tanaka T, Kondo $\mathrm{N}$, et al. Is maternal smoking during early pregnancy a risk factor for all low birth weight infants? $J$ Epidemiol 2008;18:89-96. 
14. Ward C, Lewis S, Coleman T. Prevalence of maternal smoking and environmental tobacco smoke exposure during pregnancy and impact on birth weight: retrospective study using Millennium Cohort. BMC Public Health 2007;7:81.

15. Gordon A, Raynes-Greenow C, McGeechan K, et al. Risk factors for antepartum stillbirth and the influence of maternal age in New South Wales Australia: a population based study. BMC Pregnancy Childbirth 2013;13:12.

16. Wisborg K, Kesmodel U, Henriksen TB, et al. Exposure to tobacco smoke in utero and the risk of stillbirth and death in the first year of life. Am J Epidemiol 2001;154:322-7.

17. Gardosi J, Madurasinghe V, Williams M, et al. Maternal and fetal risk factors for stillbirth: population based study. BMJ 2013;346:f108.

18. Baba S, Wikstrom A, Stephansson O, et al. Changes in snuff and smoking habits in Swedish pregnant women and risk for small for gestational age births. BJOG 2013;120:456-62.

19. Cupul-Uicab LA, Baird DD, Skjaerven R, et al. In utero exposure to maternal smoking and women's risk of fetal loss in the Norwegian Mother and Child Cohort (MoBa). Hum Reprod 2011;26:458-65.

20. Cupul-Uicab LA, Skjaerven R, Haug K, et al. Exposure to tobacco smoke in utero and subsequent plasma lipids, $A p o B$, and CRP among adult women in the MoBa cohort. Environ Health Perspect 2012;120:1532.

21. Cupul-Uicab LA, Skjaerven R, Haug K, et al. In utero exposure to maternal tobacco smoke and subsequent obesity, hypertension, and gestational diabetes among women in the MoBa cohort. Environ Health Perspect 2011;120:355-60

22. Gupta PC, Subramoney S. Smokeless tobacco use and risk of stillbirth: a cohort study in Mumbai, India. Epidemiology 2006;17:47-51.

23. Krishnamurthy $\mathrm{S}$. Maternal tobacco use and adverse reproductive outcome. Natl Med J India 1997;10:2-4.

24. Krishnamurthy S, Joshi S. Gender differences and low birth weight with maternal smokeless tobacco use in pregnancy. $J$ Trop Pediatr 1993;39:253-4.

25. Verma RC, Chansoriya M, Kaul KK. Effect of tobacco chewing by mothers on fetal outcome. Indian Pediatr 1983;20:105-11.

26. Critchley JA, Unal B. Health effects associated with smokeless tobacco: a systematic review. Thorax 2003;58:435-43.

27. Steyn K, De Wet T, Saloojee Y, et al. The influence of maternal cigarette smoking, snuff use and passive smoking on pregnancy outcomes: the Birth To Ten Study. Paediatr Perinat Epidemiol 2006;20:90-9.

28. Qiu J, $\mathrm{He} \mathrm{X}, \mathrm{Cui} \mathrm{H}$, et al. Passive smoking and preterm birth in urban China. Am J Epidemiol 2014;180:94-102.

29. Fantuzzi G, Aggazzotti G, Righi E, et al. Preterm delivery and exposure to active and passive smoking during pregnancy: a case-control study from Italy. Paediatr Perinat Epidemiol 2007;21:194-200.

30. Jaddoe VWV, Troe EJWM, Hofman A, et al. Active and passive maternal smoking during pregnancy and the risks of low birthweight and preterm birth: the Generation R Study. Paediatr Perinat Epidemiol 2008;22:162-71

31. Smith G, Pell JP, Dobbie R. Interpregnancy interval and risk of preterm birth and neonatal death: retrospective cohort study. BMJ 2003;327:313.

32. Smits LJM, Essed GGM. Short interpregnancy intervals and unfavourable pregnancy outcome: role of folate depletion. Lancet 2001;358:2074-7.

33. Ogbonna C, Woelk GB, Ning $Y$, et al. Maternal mid arm circumference and other anthropometric measures of adiposity in relation to infant birth size among Zimbabwean women. Acta Obstet Gynecol Scand 2007;86:26-32.

34. Shah R, Mullany LC, Darmstadt GL, et al. Incidence and risk factors of preterm birth in a rural Bangladeshi cohort. BMC Pediatr 2014:14:112

35. Pope DP, Mishra V, Thompson L, et al. Risk of low birth weight and stillbirth associated with indoor air pollution from solid fuel use in developing countries. Epidemiol Rev 2010;32:70-81.

36. Mannan MA, Jahan N, Dey SK, et al. Maternal and foetal risk factor and complication with immediate outcome during hospital stay of very low birth weight babies. Mymensingh Med J 2012;21:639-47.
37. Naskar N, Swain A, Das KN, et al. Maternal risk factors, complications and outcome of very low birth weight babies: prospective cohort study from a tertiary care centre in Odisha. $J$ Neonatal Biol 2014;3. doi:10.4172/2167-0897.1000142

38. Rozi S, Akhtar S, Ali S, et al. Prevalence and factors associated with current smoking among high school adolescents in Karachi, Pakistan. Southeast Asian J Trop Med Public Health 2005;36:498-504.

39. Rozi S, Akhtar S. Prevalence and predictors of smokeless tobacco use among high-school males in Karachi, Pakistan. East Mediterr Health J 2007;13:916-24.

40. Rozi S, Butt Z, Akhtar S. Correlates of cigarette smoking among male college students in Karachi, Pakistan. BMC Public Health 2007;7:312.

41. Karachi city: Geography and Demography. http://www.karachicity. gov.pk/ (accessed 10 Mar 2009). Secondary Karachi city: Geography and Demography. http://www.karachicity.gov.pk/ (accessed 10 Mar 2009).

42. Khan N, Jamal M. Maternal risk factors associated with low birth weight. J Coll Physicians Surg Pak 2003;13:25-8.

43. Gupta PC, Sreevidya S. Smokeless tobacco use, birth weight, and gestational age: population based, prospective cohort study of 1217 women in Mumbai, India. BMJ 2004:328:1538.

44. Epi-Info version 6.04; A word processing database, and statistics program for epidemiology on microcomputers. Center of disease control and prevention. Atlanta, Georgia, USA, 1995.

45. Hosmer DW, Lemeshow S. Applied logistic regression. NY: John Wiley \& Sons, 1996.

46. Ashford KB, Hahn E, Hall L, et al. The effects of prenatal secondhand smoke exposure on preterm birth and neonatal outcomes. J Obstet Gynecol Neonatal Nurs 2010;39:525-35.

47. Luo YJ, Wen XZ, Ding $P$, et al. Interaction between maternal passive smoking during pregnancy and CYP1A1 and GSTs polymorphisms on spontaneous preterm delivery. PLOS ONE 2012;7:e49155.

48. Ion R, Bernal AL. Smoking and preterm birth. Reprod Sci 2015;22:918-26.

49. Khan TA, Zaidi AK. Indoor air pollution and child health in Pakistan: report of a seminar held at the Aga Khan University Karachi Pakistan 29 September 2005. 2006.

50. Boy E, Bruce N, Delgado HN. Birth weight and exposure to kitchen wood smoke during pregnancy in rural Guatemala. Environ Health Perspect 2002;110:109.

51. Mishra V, Dai X, Smith KR, et al. Maternal exposure to biomass smoke and reduced birth weight in Zimbabwe. Ann Epidemiol 2004:14:740-7.

52. Wylie BJ, Coull BA, Hamer DH, et al. Impact of biomass fuels on pregnancy outcomes in central East India. Environ Health 2014:13:1

53. Yucra S, Tapia V, Steenland K, et al. Maternal exposure to biomass smoke and carbon monoxide in relation to adverse pregnancy outcome in two high altitude cities of Peru. Environ Res 2014;130:29-33.

54. Mishra V, Retherford RD, Smith KR. Cooking smoke and tobacco smoke as risk factors for stillbirth. Int J Environ Health Res 2005;15:397-410.

55. Sreeramareddy CT, Shidhaye RR, Sathiakumar N. Association between biomass fuel use and maternal report of child size at birth -an analysis of 2005-06 India Demographic Health Survey data. BMC Public Health 2011;11:403.

56. Cleary-Goldman J, Malone FD, Vidaver J, et al. Impact of maternal age on obstetric outcome. Obstet Gynecol 2005;105(Part 1):983-90.

57. Luke B, Brown MB. Elevated risks of pregnancy complications and adverse outcomes with increasing maternal age. Hum Reprod 2007;22:1264-72.

58. Kenny LC, Lavender T, McNamee R, et al. Advanced maternal age and adverse pregnancy outcome: evidence from a large contemporary cohort. PLOS ONE 2013;8:e56583.

59. Brown JS, Adera T, Masho SW. Previous abortion and the risk of low birth weight and preterm births. J Epidemiol Community Health 2008;62:16-22.

60. Shipton D, Tappin DM, Vadiveloo T, et al. Reliability of self reported smoking status by pregnant women for estimating smoking prevalence: a retrospective, cross sectional study. BMJ 2009;339: b4347. 